Artículo de revisión.

Cómo citar:

Editorial: Corporación Universitaria Minuto de Dios - UNIMINUTO.

Recibido: 30 de enero de 2018 Aceptado: 2 de abril de 2018 Publicado: 1 de agosto de 2018

Conflicto de intereses: los autores han declarado que no existen intereses en competencia.
Martín De la Ravanal Gómez martin.delaravanal@usach.cl Doctor (c) Filosofía Moral y Política (Universidad de Chile). Universidad de Santiago de Chile - Universidad Alberto Hurtado.

Pablo Salvat Bologna psalvat@uaburtado.cl

Doctor en Filosofía Política (Universidad Católica de Lovaina). Universidad Alberto Hurtado.

\section{En medio de las crisis: reflexiones desde la ética y la política}

\author{
Amid Crises: Reflections from Ethics \\ and Politics
}

Martín De la Ravanal Gómez, Pablo Salvat Bologna

\section{Resumen}

Este artículo de reflexión examina el concepto de crisis como categoría que da cuenta de los efectos desatinados que produce la modernización capitalista avanzada, en tanto proceso sistémico que impacta sobre las instituciones del mundo social y produce conflictos con consecuencias éticas y políticas importantes. Se analiza tanto la historia del concepto como su vínculo con las nuevas configuraciones del poder en las sociedades actuales, enfatizando en las racionalidades que impregnan el operar de los sistemas. Hacia el final, se hacen algunas propuestas normativas relativas a cuestiones como una ética crítica y emancipadora, los derechos humanos y la democracia.

Palabras clave: crisis, modernización, capitalismo, conflictos, derechos humanos.

\begin{abstract}
In this reflection paper, the authors study the concept of crisis as a category which accounts for the unreasonable effects of advanced capitalist modernization as a systemic process that has an impact on the institutions of the social world and produces conflicts with both ethical and political important consequences. They analyze the evolution of the concept as well as its connection with the new configurations of power in current society, highlighting the logics that permeate the way those systems work. At the end, they make some regulatory suggestions about topics such as a critical and emancipatory ethics, human rights, and democracy.
\end{abstract}

Key words: crisis, modernization, capitalism, conflicts, human rights.

\section{Resumo}

Este artigo de reflexão examina o conceito de crise como categoria que dá conta dos efeitos desatinados que produz a modernização capitalista 
avançada, em tanto processo sistémico que impacta sobre as instituições do mundo social e causa conflitos com consequências éticas e políticas importantes. Analisa-se tanto a história do conceito como seu vínculo com as novas configurações do poder nas sociedades atuais, destacando nas racionalidades que impregnam o operar dos sistemas. Para o final, fazem-se algumas propostas normativas relativas a questóes como uma ética crítica e emancipadora, os direitos humanos e a democracia.

Palavras-chave: crise, modernização, capitalismo, conflitos, direitos humanos.

\section{Todo está en crisis}

Hoy la palabra "crisis" está muy manida. La topamos en todos lados y debido a fenómenos bien diferentes. Es omnipresente y al mismo tiempo muy inespecífica. Sin embargo, parece una palabra que da cuenta de un rasgo ineludible de la experiencia social moderna, de tal modo que resulta difícil sustraerse de utilizarla si queremos pensar en serio nuestra sociedad.

De modo general, hay dos tipos de usos para la palabra crisis: regionales y globales. Los usos regionales obedecen a fenómenos de crisis en campos específicos como el económico, el político, el militar, el energético, medioambiental, etc. (Ricoeur, 1998; Koselleck, 2007, p. 258; Cadahia, 2012, p.178) ${ }^{1}$. Cuando se habla de crisis en un sentido global se quiere dar cuenta de una atmósfera común al horizonte de esta época moderna y contemporánea. Todo lo moderno y lo actual estaría saturado con las emanaciones de una gran crisis. La historia moderna, y nuestra contemporaneidad como efecto más cercano de ella, provocaría un malestar que daría cuenta, a través de una suerte de estado generalizado de malogro y desatino civilizatorio. La crisis, por lo tanto, aparece asociada a una patología social general, un estado de enfermedad, descomposición y decadencia de algo otrora vigoroso, saludable y vital. Esta reflexión filosófico-social sobre las patologías de la sociedad moderna comienza ya claramente en Jean Jacques Rousseau, y va conformando una idea de crisis histórica y civilizatoria (Honneth, 2009, p. 54; Koselleck, 2007, p. 252; 2012, p.133).

Desde esta perspectiva es que los teóricos y filósofos de la sociedad moderna, al menos aquellos que defienden la necesidad de una gran teoría de lo social, se esforzaron por aguzar el instrumental clínico para rastrear la fuente y momento del contagio, para prescribir las recetas apropiadas para salir de la crisis, fueran estas de tipo económico, cultural, espiritual, moral, político, etc. Esto supuso la aceptación del esquema enfermedad - salud, aplicado, esta vez, al "gran cuerpo" de la sociedad y la historia occidental, insistiendo con la consideración de la teoría como la contemplación de lo que hay en

1 La teoría social moderna, y en gran parte la filosofía social moderna, nos ha enseñado a imaginar o describir la sociedad como una especie de mega - sistema compuesto por distintos subsistemas, que desempeñarían funciones específicas a partir de un tratamiento diferenciado de ese sustrato que llamamos "sociedad" (Beriain, 1996, p. 11). A cada esfera 0 ámbito corresponderían sus particulares crisis. Lo social sería un drama compuesto por variadas crisis, entrelazadas entre ellas, emergiendo y disolviéndose a lo largo de los países y los años, sin tener, aparentemente, un fundamento o lógica común. Desde luego, los usos regionales responden, también, a la historia conceptual de la propia palabra cuyos orígenes se hunden en la Antigua Grecia (Sanchez Usanos, 2012, p. 51; Koselleck, 2012, p. 131). 
vista de un orden que se constituye en un ideal normativo ya sea entendiendo el presente como un estado de caída respecto de un pasado u origen pleno, o un estado de subdesarrollo o deformidad respecto a un modelo o estado por alcanzar en una vida o tiempo futuro (Honneth, 2009: 64 y ss.; Bauman, 2006, p. 149; Pannikar, 2014).

El concepto patológico de crisis coloca en la centralidad sus aspectos objetivos y subjetivos. Desde la perspectiva médica, cuya primera fuente es Hipócrates (1983; 1996; 2003) la percepción y padecimientos que produce el proceso de una crisis patológica tienen su fuente en fuerzas "objetivas" que están, en gran parte, fuera del control e influencia consciente del paciente. El malestar proviene de la conciencia del paciente de no hallarse en plenitud de fuerzas (Habermas, 1992, pp. 273 - 274). Esta idea de plenitud es un sentido normativo que siempre está implícito en los usos de las crisis. La expansión posterior del originario significado médico - hipocrático apuntó a dramas trágicos que se narran como conflictos y antagonismos donde se ve la libertad y la vida de los protagonistas arrestada por poderes exteriores, y cuya recuperación pasa por un rito sacrificial que involucra una transformación radical de la identidad del sujeto, llegando incluso al auto-sacrificio (Habermas, 1999, p. 20). En la modernidad, la crisis como patología de lo social va ligada a la concepción de la historia como proceso crítico. La experiencia moderna del tiempo coloca el presente como el lugar donde se precipitan los eventos novedosos y se estrecha lo dado ante el corte de la crítica y la apertura del futuro como espacio abierto de posibilidades que urge a la acción colectiva (Ricoeur, 1998; Gumbrecht, 2010, pp. 31 y 74; Koselleck, 1993, p. 333). Esto es "crisis" en sentido hegeliano: un desgarramiento entre las fuerzas conservadoras de la sociedad y las anticipaciones emancipadoras ya larvadas en el presente. El pedaleo entre crisis y critica prefigura el movimiento de la historia que Marx entenderá en clave material, es decir, por un lado, entre las contradicciones y crisis estructurales del capital -con su explotación constitutiva y estela de catástrofes sociales- y las fuerzas de la crítica, la resistencia y la revolución, por el otro (Marx, 2009; 2012, p. 384; Habermas, 2008b, p. 235; Echeverria, 2011, p. 538; Jappe, 2016, p. 113).

Marx logra efectivamente describir las crisis como procesos objetivos y, al mismo tiempo, como conflictos del mundo social con consecuencias políticas. Las crisis en el plano social se constituyen desde el encuentro entre una situación "objetiva” y una posición subjetiva, una toma de postura de alguien que podríamos llamar de manera genérica un sujeto ético-político. Este sujeto, a su vez, no emerge sino en relación con otros sujetos, con sus perspectivas y con sus posturas, configurando un campo de lo político signado por la cuestión del conflicto (Lechner, 2006, p. 173; Habermas, 2015, p. 205; Dussel, 2006, p.16, Ricoeur, 1975, p. 87). La adhesión y la convicción generan identidades al mismo tiempo que diferencias: no hay modo de decidir sino es desatando, dando expresión, al conflicto. Cada crisis, cada decisión, se da en el marco de gramáticas de conflicto y reconocimiento que son un mosaico de trasfondo que varía históricamente (Ricoeur, 1993, p. 103). Por otra parte, resulta indisociable de lo dicho la referencia a la cuestión de las instituciones de la sociedad en tanto encarnan las significaciones instituidas y son el escenario - marco de procesos instituyentes, es decir, de cuestionamiento, creación y lucha en torno a "otras significaciones" nuevas, reprimidas u subordinadas frente a las vigentes como positividades (Castoriadis, 2005, p. 64). 
Este sentido de la crisis, ligada a la cuestión del conflicto, la lucha, la decisión y el juicio fue utilizado por Aristóteles en un sentido político explícito: la krisis era la decisión que brotaba de los ciudadanos que ejercían su función en las asambleas, los tribunales y las diversas magistraturas (Aristóteles, 2015, p. 140; Balibar, 2013, p. 25). Los procesos conflictivos emergían dividiendo las aguas, desplegando pretensiones e intereses a través de posiciones que invocaban -manipuladoramente o no- lo común y lo justo. Los procesos de crisis constituían un momento soberano e instituyente desde la ciudadanía: a través de las decisiones se sellaba el destino de la ciudad y la convivencia. Esta genuina experiencia de autonomía política quedaba puesta en tensión por la deriva del pensamiento helénico que inscribía las crisis sociales y políticas en un sentido teleológico y englobante de la totalidad cósmica: el movimiento circular que combinaba fases de equilibrio y desequilibrio, debilidad y fortaleza, caos y orden, enfermedad y salud; cuyo secreto rítmico debía ser desentrañado y esclarecido por el sabio contemplativo. Los sentidos posteriores fueron debilitando esta concepción más política de la crisis cuyo centro se constituye por la cuestión de la decisión y del juicio.

\section{Crisis sistémicas y crisis sociales}

En el ámbito contemporáneo, Jürgen Habermas trabajó teóricamente el concepto de crisis, justamente dando cuenta, al mismo tiempo, de las facetas objetivas de la crisis como de su efecto en las subjetividades y consecuencias para la acción, lo que lo lleva a distinguir las crisis sistémicas de las crisis sociales. Según Habermas, las crisis son aquellos cambios en la estructura, descritas en términos de perturbaciones o colapsos sistémicos, que son experimentados como críticos por la población porque comprometen la integración social al punto de dañar la legitimidad del orden institucional (1999, p. 23). Como señalamos más arriba esta "conciencia de crisis" nunca se da como consenso unívoco sino como conflicto entre distintos grupos o actores en torno a los significados y las interpretaciones de un evento o situación cuyo modo de darse no está, por completo, a disponibilidad de la conciencia o las voluntades de ninguno de estos sujetos. La conciencia social de crisis se da en el ámbito del mundo cotidiano de la vida, es decir, en escenarios de la sociedad civil y de la opinión pública donde aún tiene sentido entender la sociedad como una experiencia de convivencia humana, por difusa que esta sea (Habermas, 2015, p. 206).

Las crisis son un proceso de reapropiación y reintepretación del sentido de la sociedad, en donde se despliegan diversas formas de señalar las consecuencias desatinadas del desarrollo social y las formas de sufrimiento individual o colectivo que éste genera. Se trata de experiencias auténticamente morales entendidas como la puesta en juego, social y comunicativa, de expectativas normativas relacionadas con el reconocimiento de la dignidad, la integridad, el honor, etc. de individuos, grupos y comunidades que, producto de la crisis, han visto o revelado dinámicas de desprecio e injusticia que les afectan (Honneth, 2011, p. 137 y ss.). Se puede decir, entonces, que las crisis nos colocan frente a frente con la configuración axiológica de una colectividad, frente a sus magmas de sentido que se desplazan en un movimiento de lo histórico-social que solidifica y fluidifica ordenes sociales (Castoriadis, 2005, p. 193). 
Las crisis solo aparecen teniendo "sentido social" si son parte del mundo compartido de una comunidad de comunicación donde pueden imaginarse y discutirse auto-comprensiones sobre la propia sociedad. Sabemos bien que los especializados y diferenciados mecanismos o medios de poder, control, coordinación no están a la vista ni a la disposición de cualquiera en la sociedad. El ciudadano/a de a pie tiene una visión mucho menos preparada técnicamente para entender o manipular su complejidad. Sin embargo, la sociedad civil y la opinión pública operan como las "antenas" o "sondas" que identifican las consecuencias desatinadas o las deformaciones de los desarrollos modernizadores (Habermas, 2008, p. 407, 1999, p. 245, Cortina, 2009, p. 144). Es por esta razón que parece una buena estrategia seguir leyendo las crisis desde una doble perspectiva: la del mundo de la vida integrado socialmente por medio de la acción comunicativa, y la de los sistemas de control y poder diferenciados funcionalmente, que coordinan instrumental y estratégicamente los intercambios sociales (Habermas, 1999, p. 25; 1993, p. 403, 1992b, p. 161; Lechner 2006, p. 515; Estrada, 2004, p. 123)

Desde la perspectiva sistémica, nuestra sociedad aparece como un entrelazamiento de poderes que son comunicados por "correas de transmisión" monetarias, legales o administrativo - burocráticas. Hay dos sistemas de poder, control y coordinación que se han levantado como los promontorios más visibles de la sociedad moderna: el estado y el mercado. En ambos encontramos un predominio de una racionalidad técnica-formalinstrumental que "gestiona" los sustratos naturales, psíquicos y sociales en función de imperativos funcionales propios: productividad, rendimiento, eficacia y eficiencia, ganancia, crecimiento, seguridad y control de la población, estabilidad, legalidad, etc. Las crisis de estos sistemas implican una pérdida cibernética de autogobierno y control, incapacidad de autorregulación y de respuesta a los cambios del entorno (Habermas, 1999, p. 21).

\section{Colapsos del sistema económico y crisis del estado}

El sistema económico queda bien descrito como un sistema de flujos cíclicos con inputs/ outputs de materias primas, mano de obra, capital fijo y variable, distribución, consumo, etc. (Habermas, 1999, p. 87; Harvey, 2012). El desarrollo global de la economía capitalista no es lineal ni armónico: por todos lados está plagado de contradicciones, arritmias y discontinuidades. Sus crisis se parecen más bien a infartos donde se corre siempre el riesgo de entumecer o paralizar los flujos de capital, trabajo y mercancías (Bensaïd, 2011, p. 122, Bauman y Bordoni, 2016, p. 11). La comprensión de la crisis como "colapso" asienta bien con la visión sistémica: se tratarían de rupturas y perturbaciones dentro de una lógica general de autorregulación y conservación de un sistema, las que muchas veces no significan un estado terminal, sino más bien momentos iterativos propios de reajuste, parcheamiento, higienizaciones, reacomodaciones y re-estructuraciones de la lógica del capital (Carrasco-Conde 2012, p.130). La economía capitalista sólo puede sobrevivir si se expande constantemente, pero con ello crecen exponencialmente los riesgos de paro cardiaco y los necesarios excesos devienen catastróficos (Zizek, 2004, p. 77). Se trata de una destrucción creativa que opera por desequilibrios multi-céntricos que van vigorizando la eficacia adaptativa y oportunista del capitalismo que cada vez más asume la máscara espectral de un mercado virtual de precios y valores financieros (Zizek, 2013, p. 139). 
El otro poder sistémico, el estado, en tanto sistema administrativo, depende de las prestaciones económicas y flujos de recaudación desde la economía, a cambio de lo cual debe proporcionar las condiciones más idóneas para que el capital se reproduzca. La alianza entre la economía capitalista y el estado, impulsada, a su vez, por las innovaciones tecnológicas y científicas, no deja de darse a pesar de la oleada neoliberal de reducciones, privatizaciones y reajustes. Ciertamente, hoy los mercados colocan imperativos de flexibilidad, apertura, eficacia, eficiencia, seguridad, privatización y competencia cada vez más exigentes. A esto ha respondido el estado con una racionalidad cada vez más tecnocrática y presuntamente despolitizada, desodorizada y neutral bajo la máscara de un tratamiento científico - social de los vaivenes económico - administrativos y las cuestiones sociales emergentes (Stavrakakis, 2010, p. 285).

En las turbulencias y maremotos económicos globales, hoy más que nunca, la economía aparece de una forma ambivalente: tanto como una inercia externa a la política, como un efecto mismo de la política económica, es decir, como un conjunto de decisiones estudiadas y conscientes, tomadas por políticos, expertos, asesores, lobistas, economistas, empresarios etc. (Zizek 2011, p. 20, Lazzarato, 2013, p. 164). El financiarizado sistema económico global aparece como una fuerza neutral, autónoma, auto-organizada que no responde a otra cosa sino a los imperativos del lucro y la ganancia codificados por señales monetarias (Touraine, 2013, p. 64). Sin embargo, al mismo tiempo, se hacen esfuerzos conscientes y planificados por encorsetar todo ámbito social a las leyes del mercado. El actual giro neoliberal del capitalismo se puede definir como el esfuerzo por propagar la lógica de mercado a cada vez más ámbitos de la sociedad (Laval y Dardot, 2013, p. 189)

La crisis del estado suele darse en el terreno de la legitimación, lo que significa que el sistema político no cuenta con los recursos para proveerse de la lealtad de los electores - ciudadanos - contribuyentes, insumos que provienen, por un lado, de la estructura normativo -institucional que rodea al estado y sus decisiones políticas, y, por otro, de la cultura política presente en la sociedad civil (Habermas, 1999, p. 202). Las crisis de legitimidad también tienen que ver con la existencia de poderes sociales (empresariales, mediales, gremiales, corporativos, partidarios, confesionales, no gubernamentales, etc.) que se autonomizan no solo del estado de derecho, sino también de las expectativas normativas de la opinión pública que toma cuerpo en redes informales de comunicación, movimientos de protesta y organizaciones no gubernamentales (Habermas, 2008, p. 468). Los núcleos de poder gubernamental en una sociedad democrática se vuelven autorreferentes y se colocan al servicio de élites económicas o directivas que no deben rendir cuentas a electores o ciudadanos. Se descuida así la calidad de la relación de las instituciones democráticas con la sociedad civil. Es pertinente hablar de una crisis de representatividad, pues las demandas y reclamos de sectores importantes de la sociedad no se ven reflejados en actos u decisiones políticas pertinentes (Salvat, 2014, p. 282). La crisis de la política democrática en su formato liberal - procedimental - formal - representativa - electoral no es tanto la inexistencia de un tinglado de principios, instituciones y procesos elementales que identificamos como "democráticos", sino el divorcio entre el poder, entendido como la capacidad de hacer cosas, y la política, entendida como la capacidad de tomar decisiones y definiciones prácticas fundamentales (Bauman, 2015,

2 Separación de poderes de Estado, elecciones universales, pluralidad de partidos, sistema electoral, etc. 
p. 85$)^{3}$. Esos estrangulamientos y constricciones que experimenta la política producen una sensación de impotencia que termina en desafección hacia la política no carente de peligros. Esto se alimenta, además, de una orientación hacia lo privado conectado con un exacerbado individualismo posesivo que choca con los compromisos y deberes hacia lo público que reclama la democracia, y se traducen, finalmente, en un confuso deseo de desintermediación respecto de las instituciones políticas (Innerarity, 2015, p. 53).

Con esto llegamos a lo que, a nuestro juicio, constituye una consecuencia central de las crisis contemporáneas: la condición de heteronomía social y su contraparte que es el déficit de autonomía política. Esta condición se expresa en la formula paradojal que elaboró Zygmunt Bauman, y que parafraseamos a propósito: La máxima libertad individual puede ser compatible con la máxima impotencia colectiva (Bauman, 2006, p.9). Esto se aplicaría especialmente, no tanto a las alternativas disponibles (que para quien dispone de recursos pueden ser inabarcables), sino más profundamente al código de elección, es decir, a las orientaciones o criterios éticos respecto a qué es lo preferible y qué decisiones son acertadas para los individuos, grupos, comunidades (Bauman, 2006, p.81) ${ }^{4}$. La acción política a la "vieja usanza" consistía en movilizar intenciones, afectos, ideas, discursos en vista de proyectos que tenían que ver con la transformación o la lucha en torno dicho código de elección. Hoy, establecido desde el mercado, no existe un programa explícito o discutido, sino un conjunto de reglas "técnico - sistémicas" que se transforman en una camisa de fuerza para ciudadanos, partidos políticos y para el mismo estado.

\section{Autonomía de los sistemas, heteronomía de lo social y racionalidad gestionaria}

A nuestro juicio, esto da cuenta de la autonomía de poderes sistémicos frente a los posibles controles político - ciudadanos. Esa autonomía sistémica puede ser definida como un cerco de operaciones, informaciones y conocimientos que da identidad a un sistema y, al mismo tiempo, lo distingue de su entorno (Castoriadis, 2005, p. 210) Esta clausura, siempre parcial y nunca perfecta, se expresa ante los miembros de una sociedad como una lógica conjuntista - identitaria: la configuración de un orden de clases, relaciones y propiedades específico con un sentido fuerte de determinación que excluye otras lógicas o sentidos distintos (Castoriadis, 2005, p. 193). Bajo esa modalidad de racionalidad, los sistemas tienden a asimilarlo todo a sus propios componentes y a reforzar su identidad diferenciándose cada vez más del entorno (Esquirol, 2011, p. 138). Esta lógica permite remitir todo fenómeno a un mismo esquema de sentido, generalmente de tipo binario,

3 Cuando la política logra armar el estado de programas o propuestas mínimamente sustantivas de cambio o transformación social se encuentra con un déficit de medios para poder incidir en el cambio de las reglas de juego fundamentales impuestas desde el sistema económico Esto se hace palpable en la frustración de la ciudadanía cuando ve al estado renunciar a regular los comportamientos de megacorporaciones y poderosos agentes económicos, o cuando los políticos plantean la imposibilidad e inconveniencia de modificar las bases del modelo económico.

4 En la modernidad "sólida" tanto la legislación como la educación eran las instancias formadoras de dichos criterios en las subjetividades. Hoy, qué duda cabe, es el mercado.

5 Luhmann añadirá que los sistemas funcionales diferenciados se constituyen por operaciones de comunicación reguladas por medios de control no lingüísticos, cuyo resultado es la agregación de acciones por mecanismos no planificados ni consensuados lingüísticamente (Luhmann, 1998; 1995). 
volviendo las diversas realidades y valores "equivalentes" entre sí, y expulsando todo aquello que no encaje en la esquemática ${ }^{6}$.

Estas modalidades de racionalidad colocan en disponibilidad técnica o instrumental los sustratos naturales, psíquicos, y sociales. Esto significa que todo puede entrar en la lógica medios - fines, y que nada es por sí mismo, sino solo es en relación con aquello que lo clasifica, lo sistematiza, lo ordena, etc. Su valor es dado desde otro lugar, no desde sí mismo (Sztajnszrajber, 2013), lo cual define la condición de heteronomía. Hoy, las racionalidades sistémicas producen efectos de heteronomía de una manera que aparece como pseudo-natural, espontánea, automática. Su apariencia es la de lo obvio, lo que encaja, lo conveniente, lo útil, lo transparente. Su realidad esconde una operación de exclusión: para que el sistema funcione, algo ha de quedar fuera, algo no ha de ser dicho, algo ha de ser proscrito. Bajo esta perspectiva, lo humano, en tanto exceso que resiste a toda completa clasificación-manipulación-disponibilidad, aparece como constante fuente de irritación y perturbación. La crisis de los sistemas son las voces y gritos de las víctimas que insisten en no callarse (Dussel, 1998, p. 257; 2016, p. 116). Esto que indicamos prefigura el avance de la racionalidad sistémica a la racionalidad gestionaria.

La clave de la racionalidad gestionaria consiste en comprender que la última frontera de colonización sistémica, las profundidades de la psique, es el lugar donde deben penetrar los imperativos sistémicos para producir lo que Byung Chul Han denomina, un "sujeto de rendimiento" que se explote a sí mismo (Han, 2012). Mientras la bio-política coloca cuerpos, órganos, poblaciones, neuronas y genes a disposición de sistemas de producción, control y gobierno; se constituye también una psicopolitica que hace lo mismo con las pulsiones, afectos, intenciones, deseos, fantasías, miedos, fobias, creatividad, etc. que se localizan en lo más íntimo de los individuos y sus relaciones elementales.

La idea de gestión indica que el propio sujeto entrega sus fuerzas internas para someterse a un mejoramiento, optimización, perfeccionamiento totalmente funcional a sus ámbitos de desempeño laboral que siguen las lógicas de mercado de productividad, competencia, expansividad, etc., bajo las apariencias de libertad, flexibilidad, autonomía e, incluso, goce. El mismo sujeto se pone a sí mismo como la fuente y objeto de dichos imperativos de rendimiento: deviene en empresario de sí mismo. Esto es impensable sin las precisas y sutiles técnicas para diseñar ambientes de rendimiento sobre la base de incentivos, motivaciones, evaluaciones, afectos, etc. que se despliegan como una cuantofrenia generalizada que es interiorizada y ejecutada libremente por el sujeto ${ }^{7}$ (Laval y Dardot, 2013, p. 325).

6 Gracias a las modalidades del lenguaje que denominó Castoriadis, legein (el decir - clasificar) y teukhein (el hacer fabricar) se realiza una "síntesis social" que produce un conjunto de objetos distinguibles, organizables, elegibles, contables, disponibles para una determinada colectividad y sus instituciones (Castoriadis, 2001).

7 Lo nuevo de todo esto reside en que parte de aquello que alguna vez resultó incómodo o desechable para los sistemas de poder y control se vuelve un objeto que quiere ser intensamente incluido y colonizado. Esto hace que el poder adquiera un "rostro humano": lo que antes eran puras relaciones instrumentales comienzan a disfrazarse bajo la apariencia de relaciones personalizadas, afectivas, éticas, simpáticas, amables, etc. (Han, 2014b). La sociedad disciplinaria da paso a una sociedad de la auto-motivación y de la afirmación de sí a través del goce e intoxicación consumista 0 mediante la exposición de la propia vida al sinóptico de las redes sociales (Han, 2014). 
Los sistemas o poderes globales que hoy dominan el mundo están animados por un magma de significaciones instituidas en el imaginario moderno que apuntan a la expansión ilimitada del dominio racional (Castoriadis, 1998, p. 135). Dicha expansión se caracteriza tanto por el ímpetu a la totalización y cierre sobre sí misma, como a la racionalidad formal-calculadora que somete lo real a una fuerte abstracción cuantificadora ${ }^{8}$. La finalidad ética implícita es la identificación del bienestar con la acumulación y la posesión, lo que a su vez se obtiene con una mayor racionalización de todos los aspectos de la vida (Castoriadis, 2007, p. 47). Desde luego esta felicidad no tiene contenido universal alguno, sino que en cada caso se define por los individuos, sus motivaciones egoístas y la capacidad de poder que colocan en la competencia social y mercantil. Los imperativos del producir, poseer, racionalizar, acumular y consumir tienen su raíz, dice Castoriadis, en una profunda inseguridad existencial (el miedo al sufrimiento y la muerte, en suma, la finitud) y a la fantasía de omnipotencia que intenta compensar esa falta o vacío espiritual (Castoriadis, 1998, p. 161 y ss.).

Como la conquista total de esos miedos no puede realizarse desde la actitud de dominación racional, la prosecución de esta lógica tiende a excederse a sí misma, a extremarse y volverse irrazonable? . Los sistemas de control y poder, sean económicos o estatales o de otra índole, ciertamente imponen heterónomamente objetivos, finalidades y procedimientos para reducir toda realidad a una misma lógica (sea económica, burocrática, bélica, etc.), pero pagan un costo que es la supresión de la riqueza, diversidad, complejidad y profundidad intrínseca de las realidades naturales, psicológicas y culturales. Rescatar esas diferencias supone cambiar la mirada ética con que nos aproximamos al mundo (Esquirol, 2006, p. 63).

\section{Dialéctica modernidad-modernización y gramáticas morales}

Aquello a lo cual nos referimos como diversas racionalidades que configuran los sistemas globales de intercambio, poder y control (instrumental, formal, técnico, sistémica, gestionaria, etc.) son el "espíritu" que impregna nuestro modo de vivir y evaluar el presente. Las crisis tienen que ver, entonces, con los grandes movimientos espirituales y materiales de la sociedad moderna, su historia, especificidad y destino, cuestión que ha sido muy relevante tanto para las filosofías de la historia como para las teorías del desarrollo. Todo esto ha ido a dar a la cuestión de la modernidad, su autocomprensión como discurso

8 El lenguaje informativo, denotativo, clasificatorio consagra un orden sistémico que se acentúa con la actual informatización de la realidad, esto permite la conversión de todo en datos que nutren sistemas de gestión, que, a su vez, apuntan a un mayor control y monitoreo social. Los sistemas informáticos de hoy no solo siguen sus programas de proceso de información: ellos aprenden y resuelven, generan nueva información. Su conexión a las tupidas redes de información les permite generar una imagen holográfica del mundo humano, llevar cada vez más fenómenos a imágenes y datos visualizables, acumulables, rastreables y manipulables, en una marea que escapa cualquier capacidad conocida para retener y comprender, y que, sin embargo, interviene al mundo.

9 El completo control de la realidad es imposible, entre otras razones, porque existen cegueras dentro de los esquemas de racionalización. Una de ellas es la heteronomía de los medios, que significa que buena parte de lo que consideramos recursos para satisfacer las necesidades de los individuos son sustratos que tienen su valor e independencia ontológica, que presentan resistencias a los fines que se les imponen y que los ordenan. La naturaleza se desequilibra, las maquinas fallan, los seres humanos cometen errores, se rebelan o se deprimen. Hay un plexo de consecuencias y efectos colaterales, ambivalentes o no contemplados que constantemente tiende a generar desorganización, descontrol, des-estructuración. 
(en particular, filosófico, ético, estético y político) y su despliegue planetario como modernización, irradiada a las periferias bajo premisas y principios forjados en sus núcleos europeos, norteamericanos, occidentales, etc. La crisis tiene que ver con la evaluación de este desplazamiento histórico moderno, con el hecho de que hemos atestiguado su ambivalencia; hemos convivido con su lado oscuro, trágico y catastrófico, que se ha ensañado con parte considerable de la humanidad.

Sin embargo, este intento de juzgar el presente da de bruces con aquellas afirmaciones que sostienen que ya no hay un punto de vista privilegiado para pronunciarse éticamente sobre lo que ocurre. La modernización estaría animada por el racionalismo occidental, cuyo sello sería la problemática separación, cada vez más acuciada, entre una racionalidad instrumental (o acorde a fines) y una racionalidad ética acorde a valores. La modernidad consumaría paulatinamente el divorcio entre ética y sociedad, renunciando a hallar mínimas orientaciones generalizables o universales para aquello que consideramos justo, correcto, bueno o siquiera deseable en los distintos sistemas imperantes. El politeísmo axiológico, tan destacado por Max Weber, resulta finalmente en un subjetivismo radical, donde cada individuo parece ser el juez último de lo bueno, conveniente y útil, sin poder esperar una fundamentación intersubjetiva y razonable de las formas de vida predominantes (Salvat, 2014, p. 289).

Siendo esto así, no habría diálogo posible entre ética, política, economía y ciudadanía. Los resultados globales de la sociedad humana, o, al menos de la "civilización occidental", en particular sus crisis, se presentarían como fenómenos pseudo-naturales e impenetrables; constricciones inmanejables e impredecibles por estados, ciudadanos, políticos y hasta por los mismos expertos. Los terremotos y tsunamis económicos, alimentarios, sanitarios, demográficos, afectarían de modo desigual a la población: mientras unos pocos, por su poder y riqueza, podrán fácilmente salvar sus vidas y patrimonio desplazándose hacia zonas más seguras, otros quedaran abandonados a sus propios, y ya precarios, recursos. Esta precariedad es solo otra faceta más del síndrome de inseguridad, desprotección e incertidumbre que acompaña nuestras experiencias sociales fundamentales recientes (Bauman, 2006, p. 13; Bauman y Donskis 2015, p. 127). Tanto el desanudamiento y fragmentación acelerada de los vínculos sociales como la privatización de los recursos de solidaridad y contención que antes eran parte de la acción colectiva o de poderes públicos, sumado todo esto al debilitamiento del Estado como figura social dominante representativa de cierta sustancia social mínima común, desata una experiencia de devastación del sentido que pulveriza la idea de habitar un mundo dotado de un mínimo de sensatez común (Lewkowicz, 2006, p. 161). Dicho vacío en las significaciones sociales haces aparecer lo siniestro: la radical inversión de lo familiar en extraño, atemorizante y hostil (Villacañas, 2013, p. 136).

A pesar de todo, estas experiencias generalizadas de sufrimiento y malestar social o podrían ser consideradas dentro de una evaluación ético-moral de los desarrollos sociales, pues, sostienen los más escépticos, careceríamos tanto de un marco compartido de nociones de justicia y bien común para poder distinguir los desarrollos atinados de los malogrados, como de una perspectiva que pueda referirse a la sociedad como un todo (Salvat, 2014, p.261). Sin embargo, las crisis sociales están lejos de ser hoy meros accidentes, colapsos parciales o traumatismos momentáneos del operar funcional de la economía 
y los sistemas políticos. Ellas impactan como acontecimientos que son interpretados y evaluados moralmente en función de las preconcepciones de bien y expectativas de justicia de los distintos grupos y sectores de la sociedad. Las crisis producen un trastorno serio en los proyectos, narrativas y prácticas de vida de los sujetos, en aquellas esferas de convivencia cotidiana más relevantes para los miembros de la sociedad (familia, escuela, trabajo, ciudadanía, etc.) Al hacerlo, brotan las expectativas morales que aparecen bajo la forma de conflictos y disputas no sólo en torno a intereses materiales y objetivos estratégicos específicos, sino también en torno al sentido que toma la sociedad, encarnada en sus instituciones, para sus miembros.

El punto de encuentro y anclaje entre los sistemas y el mundo de la vida cotidiano son las instituciones (Habermas, 1992b, p. 442, Sitton, 2006, p.242). Aquellos mundos de la vida cotidiana se diferencian en ámbitos de lo privado, lo social y lo público, y entran en contacto con el sistema económico productivo y el sistema político administrativo (Habermas, 1992b, p. 452) ${ }^{10}$. Las crisis son una forma de conciencia que es más que un instinto de alerta, ellas pueden ser la posibilidad de una nueva comprensión o transformación de lo social, lo ético y lo político al colocar en primera línea los presupuestos normativos implícitos en la convivencia social (Wang, 2014). Los colapsos sistémicos impactan heterogéneamente en los ámbitos privados, sociales y públicos. Los imaginarios que dotan de sentido a las tareas y pertenencias institucionales se vuelven gelatinosos y al fluidificarse replantean los mapas cognitivos, afectivos, morales y políticos (Bauman, 2004, p. 166; Lechner, 2006, p. 492). Estructuras y contraestructuras se hacen más visibles, los consensos son revisados a la luz de nuevos conflictos, las formas de socialización aparecen impugnadas por otras formas de sociabilidad, lo sistémico aparece diferenciándose de lo convivencial (Bauman, 2004, p.152) Esto hace posible leer las crisis desde un

10 El contacto entre lo privado y la economía da lugar al consumo que impacta sobre el espacio doméstico de la reproducción de la vida material del grupo familiar y sobre las prácticas de socialización que se llevan a cabo en él. Al mismo tiempo, el espacio íntimo privado del grupo familiar y sus relaciones más cercanas (la amistad, relaciones de amor) se abre a lo social constituido por el mundo del trabajo, el que, a su vez, está configurado desde el sistema económico-productivo (Honneth, 2009, p. 269). El espacio del trabajo nos permite identificar y pensar los vínculos intersubjetivos que se dan hacia el interior, en torno al modo en que se estructuran las tareas, los roles, las jerarquías, las distribuciones de responsabilidades, y hacia el exterior, respecto al mundo de las necesidades materiales y afectivas que provienen desde los entornos íntimo-privados. La educación, por otra parte, sería un ámbito entrecruzado tanto con la esfera íntimo-familiar como con el mundo del trabajo. Además, se abriría el mundo privado al sistema político administrativo a través de la mediación del ámbito social-público de lo comunitario, es decir, de los distintos tipos de organizaciones y agrupaciones formales e informales que se constituyen como algo distinto de la familia, distinto del trabajo y distinto de la escuela, pero, al mismo tiempo, manteniéndose profundamente vinculados a esos ámbitos. Lo público se desdoblaría tanto en su faceta estatal-jurídica y en su faceta ciudadana. Según esto seríamos, por un lado, personas jurídicas, usuarios, contribuyentes y súbditos de un aparato estatal, y, por otro, sujetos - ciudadanos que aspiran a participar y ser corresponsables soberanos del ordenamiento político de una sociedad. En cierta parte, sería legítimo equiparar este ámbito de lo ciudadano a lo político, entendiendo por esto el espacio de pluralismo y conflictividad social que va constituyendo, entre otras cosas, los sentidos normativos y expectativas morales puestas en juego por los ciudadanos, que se van instituyendo con relativa independencia de la mediación del sistema político. Ciertamente hablamos del espacio contemporáneo de la sociedad civil y la esfera de opinión pública, pero también de todas las ágoras (el espacio de encuentro público-privado) que se forman en el ámbito educativo, laboral, comunitario, barrial, etc. La posibilidad de la política como actividad lúcida y reflexiva de cuestionamiento, crítica y transformadora de lo instituido en la sociedad, se da en este espacio de lo políitico que parece resistirse a ser absorbido por el sistema político (o sea, la política en tanto mediación institucional). 
punto de vista evaluativo-normativo que adopta la forma de conflictos y luchas por el reconocimiento (Honneth, 2011, p. 63).

Las esferas del trato cercano (familia-amistad), de la ciudadanía y la solidaridad social (en especial el mundo social del trabajo) aún bajo su forma actual, tienen patrones de expectativas normativas, diferenciadas según grupos y sectores, relativas al tipo y calidad de relaciones que esperamos establecer en nuestra convivencia. Cuando se violan dichos patrones, aparecen experiencias de desprecio y agravio moral que identificamos como el maltrato físico y la humillación psicológica en la esfera del trato cercano (familiar); la discriminación y privación de derechos en la esfera público-ciudadana; y el menosprecio de las tareas, roles, capacidades, desempeños y formas de vida de individuos, grupos y comunidades en la esfera de la solidaridad social, que incluye los ámbitos del trabajo, la educación y la pertenencia a diversas organizaciones y redes comunitarias (Honneth, 2010, p. 23). Desde luego, estas expectativas se realizan bajo ciertas pretensiones de validez y legitimidad que hacen que dichas demandas levantadas a las instituciones y a los grupos dominantes no sean meras expresiones particulares de intereses, sino posturas razonables que apuntan, de uno u otro modo, a visiones de justicia social y política que debieran inspirar las estructuras e instituciones políticas de la vida en común (Honneth, 2010, p. 47). Es absolutamente necesario que en una democracia dichas visiones puedan, al menos, expresarse, discutirse y criticarse públicamente.

Las contradicciones de los sistemas sociales - manifestadas como crisis económicas, por ejemplo - penetran, por medio de las instituciones, en las formas de vínculos y trato entre individuos, grupos y comunidades. Los problemas de los sistemas son percibidos y gestionados como riesgos organizacionales. Su acumulación y sobresaturación es traducida en esos espacios convivenciales como crisis, lo que usualmente va acompañado de un sentido de peligro inminente, de inseguridad, de pérdida de fuerzas de respuesta, de paralización de la capacidad de reacción, que se resumen en tres nociones: perturbación, crecimiento del desorden e incertidumbre y bloqueo/desbloqueo de funciones, fuerzas y energías (Morin, 1994, p. 192). En este sentido, las crisis son tomadas como un quiebre de normalidad, en cuanto aquello tomado por seguro y habitual ya no puede serlo (Bauman, 2006, p. 151). El efecto de desestructuración, al resonar en los espacios intrapsíquicos e intragrupales va notificándose como malestar que desborda lo meramente subjetivo para convertirse en fenómeno intersubjetivo. Junto con el elemento afectivo, aparece el elemento ético-moral, pues el malestar da cuenta de expectativas éticas (relativas a la buena vida, a lo justo y al reconocimiento) que están siendo incumplidas o malogradas (Honneth, 2009, p. 261). Al ocurrir todos estos fenómenos en ámbitos de vida en sociedad (lo íntimo-familiar, el consumo, el trabajo, la educación, lo comunitario, lo estatal, lo ciudadano) que son esferas de reconocimiento, las crisis aparecen como conflictos sectoriales que son interpretados de maneras diferentes, pero que al mismo tiempo "narran" una cierta atmósfera global de malestar. Eso ocurre, desde luego, si logran alcanzar un nivel de reflexión adecuado, y dichas posturas no son neutralizadas o reprimidas desde estrategias despolitizadoras o represivas (Villacañas, 2013, p. 135, Balibar, 2013, p. 168, Laval y Dardot, 2017, p. 34)

Los circuitos de poder, control, coordinación e intercambio sistémico logran, como hemos visto, articular de manera estable, en una extensión espacio-temporal de larguísimo alcance, innumerables nodos de organizaciones e instituciones donde conviven los 
sujetos sociales. Este factor humano-convivencial, en sus diversos ámbitos ya descritos, es un "entorno" en el que se mueven los mercados, las grandes redes corporativas, los sistemas políticos, etc (Laval y Dardot, 2017, p. 127) Este entorno puede ser gestionado tranquilamente, pero también puede dar lugar a irritaciones y urticarias sistémicas. Las crisis sociales reingresan a los sistemas como factores o ingredientes del entorno que hacen más complejo el logro de los objetivos funcionales, pues deben incorporarse nuevas variables a los cálculos estratégicos. Durante la etapa más tardía del siglo XX, estados, empresas, corporaciones, organizaciones militares, complejos productivos, etc. debieron estar cada vez más atentos a los ingredientes culturales, ético-morales, políticos, religiosos e incluso estéticos de los grupos humanos. Combinado lo anterior con regímenes democráticos apertrechados con ciertas libertades de expresión y formas de comunicación cada vez más instantáneas y accesibles, se ha dado lugar a la visibilidad creciente de conflictos y crisis que antes permanecían latentes.

Las crisis sistémicas devienen crisis sociales cuando alcanzan a ser traducidas bajo las distintas gramáticas morales y expectativas éticas de los grupos y comunidades (Habermas, 1999, p. 23). Al tomar forma de expresiones públicas relativamente estables, por medio, por ejemplo, de organizaciones de la sociedad civil o movimientos sociales, pueden interpelar al poder institucionalizado apareciendo como crisis con carácter político. Si el sistema político no es capaz de resolver las demandas con sus medios sistémicos, aparecen las crisis políticas propiamente dichas. Estas últimas son las crisis de las estructuras de la vida en común donde existe un poder institucionalizado y se toman decisiones que afectan globalmente a la población. La crisis política sería, en un primer momento, una pérdida de la capacidad de asegurar las condiciones para la conservación de un orden mínimamente aceptable para la población. En una segunda instancia, una crisis política es una crisis de legitimidad: el sistema político ya no logra suscitar obediencia, lealtad o conformidad entre los ciudadanos. En una tercera instancia, la crisis política genera una crisis del sentido institucional: la conflictividad creciente pone en cuestión no sólo los mecanismos y procedimientos establecidos para el poder, sino los valores y funciones más generales de las instituciones sociales para el ordenamiento de la sociedad ${ }^{11}$.

Las crisis no se tratan hoy solamente de fenómenos o ficciones de comunicación. Podemos afectar más que nunca las condiciones de posibilidad de reproducción material de nuestra especie e incluso la posibilidad de conservación de la vida en general ${ }^{12}$. Las crisis ecosistémicas impactan sobre las condiciones de operación de los sistemas económicos, productivos y de consumo, lo que a su vez pone en aprietos a los sistemas administrativos estatales que deben activar dispositivos de contención y control de estos fenómenos emergentes. El lado trágico de estas crisis es que suelen traer consigo los males

11 Este último fenómeno es especialmente complejo: Ia desafección puede llegar a niveles de un rechazo indiferenciado de toda mediación institucional, que al exacerbar los particularismos destruye no solo la posibilidad de la justicia (que prevalece, como señaló Platón incluso en una banda de ladrones), sino toda la acción política en general. Este proceso disolutivo implica la entrada de un tipo de violencia indiferenciada, insensata, dominada absolutamente por pulsiones de muerte y que es, sin lugar a duda, regresiva.

12 Las catástrofes ecológicas y climáticas impactan directamente sobre las poblaciones humanas de manera desigual, pues una parte de las sociedades ricas está mejor preparada, que la mayoría de las sociedades pobres, para soportar las oleadas de calor, los huracanes, las sequías, los gigantescos incendios forestales, las lluvias torrenciales, la falta de alimentos, las plagas de insectos o las heladas implacables. De ahí que algunos estén hablando de apartheid climático. 
concretos de la insatisfacción general de necesidades básicas materiales, la destrucción o la privación de bienes esenciales para la población. El lado positivo es que esas dificultades pueden traer ensayos de nuevas formas de solidaridad y convivencia, producir percepciones de la realidad y formas de conciencia enriquecidas, desatar fenómenos de creación e institución de lo social, reconsideración general de los valores e instituciones vigentes. Pero entre la crisis y esta exploración novedosa de posibilidades de acción, deben darse condiciones de reflexión y de trato social particulares. No toda crisis traerá un sujeto ético político afirmativo.

\section{Reflexiones finales}

La palabra crisis en su sentido griego original (krisis) pasó de la medicina hipocrática a los campos políticos y jurídicos, y significaba decisión, juicio, criterio, distinción, elección, determinación. Apuntaba también a la idea de lucha, conflicto, separación, etc. La dimensión temporal también estaba incorporada, indicando tanto la situación de decisión y el mismo acto de elegir, como la idea de momento de cambio, ruptura de la habitualidad-normalidad, punto de inflexión, giro o vuelco repentino en la acción (lo que se acerca mucho a la idea de catástrofe en la tragedia griega). Por el contrario, crisis significa hoy un estado fundamentalmente de indecisión. Esto alude, desde luego, a la cuestión de la acción política: se espera todavía de ella una capacidad de respuesta y acción ante los desastres económicos, demográficos, sanitarios, medioambientales, etc. La acción política no se reduce a la acción estatal. Significa la capacidad de actuar juntos con posibilidades de incidir y decidir sustancialmente sobre las maneras en que se organiza la sociedad en sus distintos aspectos.

La acción política necesita apoyarse en una visión politica: una perspectiva afirmativa de aquellas potencialidades históricas que tiene una sociedad para resolver sus desarrollos desatinados y expandir las posibilidades de libertad, justicia, igualdad y dignidad para sus miembros. Dicha visión no es, ni puede ser, una postura neutral éticamente ni tampoco una mera forma ideológica. Debería orientarse a ser aquello que Cornel West ha llamado compromiso profético: una manera de ser en el mundo que coloca mente y corazón en la respuesta a quienes demandan atención por su sufrimiento y dolor, o que viven profundamente ahogados en la injusticia y la opresión. La visión política nace desde esta sensibilidad ética que coloca en primer lugar la dignidad, la justicia y la responsabilidad entendida como cuidado de los seres humanos que sufren (West, 2011, p. 96). Una mirada ética de la política que no sea fagocitada por un absolutismo de la convicción o por un raquítico pragmatismo, se sitúa en una posición de inquietud ética, respecto a las prioridades que ha de tener nuestra acción y la jerarquía de valores que ha de prevalecer cuando se trata de situaciones críticas y del sufrimiento humano que merece atención en tales circunstancias.

Ahora bien, ¿en torno a qué nuevo horizonte práxico-ideal podría irse nucleando ese "compromiso profético" que nos demanda West ante el desbarajuste del presente? No es fácil dar respuestas unívocas. Las "ofertas" existentes no son pocas. El tema, en todo caso, no es solamente de ofertas más o menos estructuradas, sino también, quizá en primer lugar, de que la sociedad, sus agentes de cambio posible, se convenzan de que puede haber alternativas frente a lo que parece un destino marcado por lo ineluctable. Pero modificar esa percepción será producto de un trabajo histórico-real -cultural, de recreación de un 
ethos-, y no solamente, de la elaboración de un buen sistema de ideas. O, si se quiere, de que el nuevo paradigma emancipador sea capaz de anclarse y arrancar de la actual experiencia de mundo bajo el dominio de una racionalidad globalizante y neoliberalista que, de paso, para colmo, se pretende única y final.

Creemos que un horizonte normativo como el de los Derechos Humanos (en adelante $\mathrm{DDHH}$ ) se conforma hoy como un reto primordial para una humanidad en crisis. Sin embargo, esta misma crisis no es solo de aspectos secundarios u ornamentales. Revela los límites de la racionalidad profunda que atraviesa los principales sistemas organizadores de la vida diaria (estado y mercado) Ante el observador de nuestra época, se vuelven inocultables las numerosas formas de negación de necesidades humanas que están relacionadas, de una u otra forma, con la expresión y expansión de esa singular alianza entre capitalismo (libre mercado autorregulado), ciencia y técnica. Ante el politeísmo de valores y ópticas procesadoras de eventuales opciones es que una asunción crítica de los DDHH, como expresión del bien común de la contemporaneidad, nos puede servir de brújula orientadora ante las crisis actuales.

Los DDHH pueden convertirse en pauta o criterio ético-político, cultural, de una nueva racionalidad y una nueva ciudadanía, pero para ello tenemos que sobrepasar la ideología de mercado, ciencia y técnica imperante convertida en sistema sin sujeto. Para esto sería importante avanzar hacia una comprensión de los derechos como un proceso, social/histórico, cultural, institucional, por medio de los cuales se expresa y avanza en el logro de una sociedad basada en la dignidad de las personas, la promoción de la justicia y el bien común. La singularidad es que los $\mathrm{DDHH}$ así entendidos, pueden funcionar como idea reguladora a través de la cual se expresan -de distintas formas y en diferentes tiempos históricos -, las constantes búsquedas y luchas de la humanidad por un real acceso a aquellos bienes materiales e inmateriales que recuperen y posibiliten libertades, justicia y dignidad. Los DDHH pueden pensarse, además, como foco articulador de un nuevo tipo de racionalidad integradora que coloque en su centro, una ética de la responsabilidad solidaria (o de un bien común que subordine medios y fines particulares). Desde este punto de vista entonces, podemos poner a los DDHH como una expresión de las dinámicas sociales que empujan desde abajo en las sociedades por el logro de condiciones de vida que permiten un adecuado acceso a los bienes sociales fundamentales y, al mismo tiempo, por lograr recapturar expresiones de dirección democrática que permitan una vida digna para todos.

Pues bien, lo que va resultando cada vez más claro en el presente es la revelación de la incompatibilidad entre capitalismo -neoliberalista- $y$ democracia. En verdad, si uno se atiene a las condiciones históricas el capitalismo siempre ha tenido dificultades para convivir con un concepto ampliado y radical de democracia. Su momento de mayor ampliación de derechos ciudadanos fue después de la Segunda Guerra Mundial, acicateado, no solo por las reclamaciones de los movimientos de trabajadores, sino también por la amenaza que representó la primera revolución socialista en la modernidad (1917). Todo esto permitió la génesis de lo que se llamó el Estado social o el Estado de Bienestar, donde algunos derechos sociales revindicados pudieron garantizarse y cumplirse, al menos en los países más desarrollados económica y políticamente. Este cuadro terminó con la crisis de ese capitalismo predominante a mediados de los setenta y con el ascenso de un liberalismo más agresivo, promotor de una anti-regulación económica y una despolitización 
social. También, coadyuvó ciertamente la caída de la experiencia de la URSS y el campo socialista. A partir de allí, las condiciones para los ciudadanos comenzaron a modificarse, así como también para la política misma. Con la distancia que tenemos de los últimos años del siglo pasado, y los que van del nuevo, quizá tendríamos que interrogarnos: ¿no será que la victoria del capitalismo - como se celebró en 1989-, ha traído, al mismo tiempo, la derrota de la democracia? (Balibar, 2017).

En el marco del actual capitalismo financiarizado y globalizado, la única expresión política que cabe es la de una democracia maniatada y limitada; protegida de cualquier alternativa que altere las bases de la economía de mercado y el electoralismo contingente. De allí al desencanto y desconfianza actualizado y el renacimiento de grupos fascistoides, fanáticos, fundamentalistas y similares, no hay demasiado trecho. Con esto, y no podemos desarrollarlo aquí, queremos expresar que el reconocimiento y realización gradualista de un horizonte de derechos humanos, no es factible desde la perspectiva del capitalismo neoliberalizado y globalizado actual, así como tampoco de sus representantes políticos. Por eso, habría que apostar por rescatar un nuevo republicanismo, un republicanismo democrático, que ponga el acento en un régimen democrático que vaya más allá de su posición como mero juego de unas reglas procedimentales que se comparten. Aquí el ideario democrático no se reduce a ser un buen método para escoger representantes de una élite que gobernará por cierta cantidad de años. El republicanismo democrático pone en juego una idea "fuerte" de democracia.

Esto implica, entre otras cosas: a) concebir la actividad política como posibilidad de intervención activa, compartida, colectiva, de manera deliberativa, sobre nuestro destino en común. Solo desde la vida pública es que podemos ejercer nuestras capacidades humanas para hacernos cargos -en común- de nuestra propia historia; b) que la anhelada autonomía ciudadana no puede obtenerse sin autonomía de la colectividad; c) promover una idea de libertad que se entiende como no-dominación y capacidad de autogobierno, personal y comunitaria; d) esta idea de libertad en la tradición republicanista parte de la prioridad ontológica de la sociedad sobre el individuo, y como tal, observa que libertad e igualdad van juntas, son no-separables. Desde el republicanismo democrático, la igualdad mienta un principio normativo que garantiza a todo sujeto disponer por igual de recursos y bienes, materiales y espirituales, que le permitan el mismo grado de control sobre la vida en común y sobre su propia vida. Y, claro, tendrá aquí un lugar importante la igualdad material. Por eso, la justicia y los derechos sociales van, desde esta óptica, de la mano. Ahora bien, proponer una idea "fuerte" de democracia y de Estado, implicará también la reivindicación de una ciudadanía activa, comprometida, mediante la cual se crea una comunidad solidaria, atenta al reconocimiento de las demandas y necesidades del todo, en particular, de los más desposeídos o frágiles. Ciertamente, la posibilidad de asumir e ir encarnando el conjunto de los derechos humanos -en función del bien de las mayorías y del ideario de la igualdad, solidaridad y fraternidad-, es algo no alcanzable bajo el dominio del capitalismo neoliberalizado y de sus instituciones ${ }^{13}$.

13 Por eso, sostenemos que el encarnar un proyecto como el del republicanismo democrático, solo será posible bajo lo que llamamos, socialismo. Estamos conscientes que, mentar un término como éste, suscita inmediatas reacciones y discusiones, que no podemos desarrollar aquí y queda como tarea de un pensar crítico colectivo. Lo importante es colocar estas reflexiones bajo la demanda de un nuevo paradigma de emancipación que requerimos como sociedad y humanidad. 
No se trata de ver en estas propuestas prioridades y jerarquías cerradas, sino apuestas éticas situadas en apertura a las críticas, al diálogo, a la reflexión, de cara a la finitud y falibilidad humanas y puestas en obra en frágiles experimentos democráticos. La visión política ha de complementarse con un compromiso socrático con la democracia, es decir, colocar en la centralidad de nuestra experiencia el cuestionamiento de lo dado, la interrogación permanente, la apertura a propuestas y perspectivas ajenas, el amor por la sabiduría, etc. que sacuda el conformismo, la ignorancia, el fanatismo, la cobardía y la complacencia (West, 2008, p. 197). El compromiso democrático exige una ciudadanía vigilante de poderes y élites (gubernamentales, corporativas, oligárquicas, mediales, confesionales, etc.) que han dejado de rendir cuentas a la ciudadanía, volviéndose autorreferentes respecto a sus objetivos; ciegos frente a las consecuencias de sus actuaciones; abusivos y traidores a la confianza social depositada inicialmente en ellos. Pero, indudablemente la visión política no ha de quedarse solo con la indignación y justa rabia contra la injusticia: ella ha de dar paso a una posición afirmativa que sepa rastrear y coordinar las fuerzas y energías sociales (cognitivas, morales, religiosas, artísticas, técnicas, etc.) en un proyecto de transformación que conjugue lo deseable, lo realizable y lo razonable.

Queda por ver aun si las recientes crisis han comenzado a esbozar estas necesarias visiones o si por el contrario han reforzado la resignación, la apatía y la desafección. Caso de ser así, no son buenos los augurios para las mayorías pobres y excluidas de la humanidad. Por eso, el deber de reflexionar y comprender las crisis y, al mismo tiempo, levantar paradigmas alternativos, es una tarea urgente y de largo aliento.

\section{Referencias}

Aristóteles. (2015). La Política. Madrid: Alianza.

Balibar, É. (2013). Ciudadanía. Buenos Aires: Adriana Hidalgo editora.

Balibar, É. (2017). “De la victoria del capitalismo a la derrota de la democracia?”. Entrevista. Marc Verzeroli/Olivier de France. Nueva Sociedad No. 271, Extraída de: www.nuso.org

Bauman, Z. (2004). Ética Posmoderna. Buenos Aires: Siglo XXI.

Bauman, Z. (2006). En busca de la política. Buenos Aires: Fondo de Cultura Económica.

Bauman, Z. y Donskis, L. (2015). Ceguera Moral. La pérdida de sensibilidad en la modernidad líquida. Buenos Aires: Paidós.

Bauman, Z. y Bordoni, C. (2016). Carlo. Estado de crisis. Barcelona: Paidós.

Bensaïd, D. (2011). Marx ha vuelto. Buenos Aires: Edhasa.

Beriain, J. (comp.). (1996). Las consecuencias perversas de la modernidad. Barcelona: Anthropos

Cadahia, L. (2012). El dispositivo de la crisis como Nuevo Orden Mundial. En Cadahía, Luciana y Velasco, Gonzalo (comps.) (2012). Normalidad de la crisis/crisis de la normalidad. Buenos Aires: Katz editores.

Castoriadis, C. (1998). Hecho y por hacer. Pensar la imaginación. Buenos Aires: Eudeba.

Castoriadis, C. (2001). La institución imaginaria de la sociedad. Buenos Aires: Tusquets Editores.

Castoriadis, C. (2001b). Figuras de lo pensable (Las encrucijadas del laberinto VI). Buenos Aires: Fondo de Cultura Económico. 
Castoriadis, C. (2005). Los dominios del hombre. Las encrucijadas del laberinto. Barcelona: Gedisa.

Castoriadis, C. (2007). Democracia y relativismo: debate con el MAUSS. Buenos Aires: Editorial Trotta.

Carrasco-Conde, A. (2012). Blow up. Evento, acontecimiento, crisis. En Cadahía, L. y Velasco, G. (compiladores). Normalidad de la crisis/crisis de la normalidad. Buenos Aires: Katz editores.

Cortina, A. (2009) Ciudadanos del mundo. Hacia una teoría de la ciudadania. Madrid: Alianza.

Dussel, E. (1998). Ética de la liberación en la Edad de la Globalización y la Exclusión. Madrid: Trotta.

Dussel, E. (2006). 20 tesis de política. México: Siglo XXI - Centro de Cooperación Regional para la Educación de Adultos en América Latína y el Caribe.

Dussel, E. (2016). 14 tesis de ética. Hacia la esencia del pensamiento critico. Madrid: Trotta.

Echeverría, B. (2011). Crítica de la modernidad capitalista. La Paz: Vicepresidencia del Estado Plurinacional de Bolivia.

Esquirol, J. M. (2006). El respeto o la mirada atenta. Barcelona: Gedisa.

Esquirol, J. M. (2011). Los filósofos contemporáneos y la técnica. Barcelona: Gedisa.

Estrada, J. A. (2004). Por una ética sin teología. Habermas como filósofo de la religión. Madrid: Editorial Trotta.

Gumbrecht, H. U. (2010). Lento presente. Sintomatología del nuevo tiempo histórico. Madrid: Escolar y Mayo.

Habermas, J. (1992). La reconstrucción del materialismo histórico. Madrid: Taurus Editorial.

Habermas, J. (1993) El discurso filosófico de la modernidad. Madrid: Taurus.

Habermas, J. (1992b). Teoría de la Acción Comunicativa II: Crítica de la razón funcionalista. Madrid, Editorial: Taurus.

Habermas, J. (1999). Problemas de legitimación en el capitalismo tardio. Madrid: Cátedra. Habermas, J. (1999b). La inclusión del otro. Madrid: Editorial Paidós.

Habermas. J. (2008). Facticidad y validez. Sobre el derecho y el Estado Democrático de derecho en términos de teoría del discurso. Madrid: Trotta.

Habermas, J. (2008b). Teoría y praxis. Estudios de filosofía social. Madrid: Tecnos

Habermas, J. (2015). Mundo de la vida, politica y religión. Madrid, Trotta.

Han, B. C. (2012). La sociedad del cansancio. Barcelona: Herder.

Han, B. C. (2014). En el enjambre. Barcelona: Herder.

Han, B. C. (2014b). Psicopolitica. Neoliberalismo y nuevas técnicas de poder. Barcelona: Herder.

Harvey, D. (2012). El enigma del capital y las crisis del capitalismo. Madrid: Akal.

Hipócrates. (1983). Tratados hipocráticos I. Madrid: Gredos.

Hipócrates. (1986). Tratados hipocráticos II. Madrid: Gredos.

Hipócrates. (2003). Tratados hipocráticos VIII. Madrid: Gredos.

Honneth, A. (2009). Critica del agravio moral. Patologias de la sociedad contemporánea. Buenos Aires: Fondo de Cultura Económica.

Honneth, A. (2010). Reconocimiento y Menosprecio. Sobre la fundamentación normativa de una teoría social. Buenos Aires: Katz.

Honneth, A. (2011). La sociedad del desprecio. Madrid: Editorial Trotta. 
Innerarity, D. (2015). La politica en tiempos de indignación. Barcelona: Galaxia Gutenberg.

Jappe, A. (2016). Las aventuras de la mercancía. La Rioja: Pepitas de calabaza.

Koselleck, R. (1993). Futuro pasado. Para una semántica de los tiempos históricos. Barcelona: Paidós.

Koselleck, R. (2012) Historia de conceptos. Estudios sobre semántico y pragmática del lenguaje. Madrid: Trotta.

Lazzarato, M. (2013). Gobernar a través de la deuda. Tecnologías de poder del capitalismo neoliberal. Buenos Aires: Amorrortu.

Laval, C. y Dardot, P. (2013). La nueva razón del mundo. Ensayo sobre la sociedad neoliberal. Barcelona: Gedisa.

Laval, C. y Dardot, P. (2017). La pesadilla que no acaba nunca: el neoliberalismo contra la democracia. Barcelona: Gedisa.

Lechner, N. (2006). Las sombras del mañana. Obras Escogidas, Tomo 1. Santiago: LOM.

Lewkowicz, I. (2006). Pensar sin estado. La subjetividad en la era de la fluidez. Buenos Aires: Paidós.

Luhmann, N. (1995). Introducción a la teoría de sistemas. México: Universidad Iberoamericana.

Luhmann, N. (1998). Complejidad y modernidad. Madrid: Trotta.

Marx, K. (2009). Las crisis del capitalismo. Madrid, Sequitur.

Marx, K. (2012). Textos selectos. Madrid: Gredos.

Pannikar, R. (2014). La religión, el mundo y el cuerpo. Barcelona: Herder.

Morin, E. (1994). Sociología. Madrid: Tecnos.

Ricoeur, P. (1975). "El conflicto: ¿signo de contradicción y unidad?” en LADRIERE, Jean y Ricoeur, Paul. Poder y conflicto. Santiago: Instituto de Estudios Políticos (IDEP), Editorial del Pacífico.

Ricoeur, P. (1993). Amor y justicia. Madrid: Caparrós editores.

Ricoeur, P. (1998). La crise: un phénomène spécifiquement moderne?. Revue De Théologie Et Philosophie, (120), pp.1-19.

Salvat, P. (2014). Max Weber: poder y racionalidad. Hacia una refundación normativa de la politica. Santiago: RIL editores

Sanchez Usanos, D. (2012) Modernidad, crisis y filosofía, en Cadahía, L. y Velasco, G. (comp.) Normalidad de la crisis/crisis de la normalidad. Buenos Aires: Katz editores.

Sitton, J. (2006). Habermas y la sociedad contemporánea. México: Fondo de Cultura Económica.

Stavrakakais, Y. (2010). La izquierda lacaniana: psicoanálisis, teoría, politica. Buenos Aires: Fondo de Cultura Económica

Sztajnszrajber, D. (2013). ¿Para qué sirve la filosofía?. España: Planeta.

Sitton, John (2006). Habermas y la sociedad contemporánea. México: Fondo de Cultura Económica.

Touraine, A. (2013). Después de la crisis. México: Fondo de Cultura Económica.

Villacañas, J. L. (2013). Crisis: un ensayo de definición. Vinculos de Historia, 2. Pp. 121 -140 .

Wang, T. (2014). A Philosophical Analysis of the Concept of Crisis. Frontiers of philosophy in China, 9(2), pp. 254-267.

West, C. (2008). Asuntos democráticos. Caracas: Editorial El perro y la rana. 
West, C. (2011). Prophetic Religion and the Future of Capitalist Civilization en Butler, J., Habermas, J., Taylor, CH., West, C. The Power of Religion in the Public Sphere. New York: Columbia Press.

Žižek, S. (2004). Repetir Lenin. Madrid: Akal.

Žižek, S. (2011). Primero como tragedia, después como farsa. Madrid: Akal.

Žižek, S. (2013). El año en que soñamos peligrosamente. Madrid: Akal. 